\title{
Effect of Culture Media for Anther Culture of Indica Rice Varieties and Hybrids of Indica and Japonica
}

\author{
${ }^{* 1}$ H.M.I. Herath , ${ }^{2}$ D.C. Bandara and ${ }^{3}$ P.K. Samarajeewa \\ ${ }^{1}$ Postgraduate Institute of Agriculture, University of Peradeniya, Sri Lanka \\ E-mail: indra_herath@yahoo.com \\ ${ }^{2}$ Department of Agricultural Biology, Faculty of Agriculture, University of Peradeniya, Sri Lanka \\ ${ }^{3}$ Plant Genetic Resources Centre, Gannoruwa, Peradeniya, Sri Lanka
}

Accepted $5^{\text {th }}$ September 2007

\begin{abstract}
Pollen plants from anther culture in rice breeding allows selection of fine strains in early generations. Exploitation of anther culture technique in research is limited due to very low regeneration frequency of indica cultivars and the transfer of anther culture traits from japonica to indica varieties is important in improving these rice varieties. In this study the optimization of media requirements and culture conditions for high frequency callus induction and plant regeneration of several indica $\times$ japonica $F 1$ hybrids were evaluated using improved anther culture media. Five indica rice varieties ( BG 90-2, BG 379-2, BG 94-1, Dahanala and Suduru samba) and two japonica varieties (Hu Lo Tao and Chuan 4) were selected and F1 hybrids were taken with all possible crosses between them. Panicles were cold pre treated at $5^{\circ} \mathrm{C}$ for 7 days and anthers were cultured in agar solidified modified N6, B5 and Millers media. Calli were transferred to MS medium for plant regeneration. Best callus induction frequencies $(0.8-$ $29.4 \%)$ were obtained in N6 medium containing $5 \%(\mathrm{w} / \mathrm{v})$ sucrose, than B5 $(0.5-19.2 \%)$ and Millers $(0.2-19.8 \%)$ media. The F1 hybrids were more responsive to anther culture than their parents. Highest callus induction frequency of $29.4 \%$ could observe in N6 medium for F1 hybrid Hu Lo Tao $\times$ BG 90-2. The green plant regeneration frequency of calli induced on N6 medium was higher than the other two media and the highest frequency of $41.0 \%$ was occurred in F1 hybrids of Hu Lo Tao $\times$ BG 90-2. Green plants were transferred to pots with $50-75 \%$ survival rate. Out of 99 plants survived, 28 plants had more than 5\% spikelet fertility. Modified N6 medium had positive effect on anther culture performance and the F1 hybrid Hu Low Tao $\times$ Bg 90-2 had the best performance.
\end{abstract}

Key words: anther culture, indica, japonica, modified media, plant regeneration, rice

\section{INTRODUCTION}

Anther culture as a method of creating haploid strains has become greatly useful in genetic studies and practical breeding (Yi, 1991). Double haploid systems have the unique genetic property of producing completely homozygous lines from heterozygous parents in a single generation (Snape, 1989). Using pollen parents from anther culture in rice breeding can reduce breeding time, increase selection efficiency and save space and labour in the field by allowing selection of fine strains in early generations (Shih-Wei and Zhi-Hong, 1991). This system provides an unparalleled opportunity to shorten the breeding cycle and fix agronomic traits in the homozygous state, such as recessive genes

\footnotetext{
*Corresponding author
}

for disease resistance (Datta, 2005). In a study conducted by Senadhira et al., (2002), in Sri Lanka, they could identify salt tolerant anther culture derived rice lines within three years time.

Rice has become one of the few crops in which anther culture can be rapidly applied in breeding programs (Chen et al., 1991). Extent of success of haploid induction depends on a number of factors that include genotype, developmental stage, cultivated conditions of plants, components of culture medium, pre treatments etc. (Shih-Wei and Zhi-Hong, 1991; Balachandran et al., 1999; Wang et al., 2000; Datta, 2005).

Exploitation of anther culture technique in breeding and genetics research is limited due to 
very low regeneration frequency of anthers of rice in general, and indica cultivars in particular (Balachandran et al., 1999). As Zhang (1989) stated, there is relatively over dominance for culture ability and therefore making the cross combinations among the parents with different culture abilities can overcome the culture difficulties. Research efforts on the enhancement of response to anther culture have been confined mostly on manipulation of callus induction and plant regeneration protocols (Balachandran et al., 1999). According to Reddy et al. (1985), the application of N6 medium to indica rice was found to be limited although it is quite suitable for japonica rice. Therefore attempts were made to modify this medium in order to improve its suitability.

High yielding and traditional rice varieties grown in Sri Lanka belong to indica type and they respond poorly to anther culture. Transfer of anther culture traits from japonica to indica varieties is important in improving rice varieties. In this study the objective was to evaluate the response of anthers of selected indica (high yielding varieties and traditional varieties), japonica varieties and their inter sub specific F1 hybrids for high frequency callus induction and plant regeneration in different culture media with certain modifications.

\section{MATERIALS AND METHODS}

\section{Plant material}

Seeds of the two japonica and five indica rice varieties were collected from Plant Genetic Resources Centre, Gannoruwa, Sri Lanka (Table 1). They were grown in pots in a greenhouse with providing standard agronomic conditions from June to November, 2002. The indica, and japonica varieties were crossed and $\mathrm{F} 1$ hybrids were produced in 2002. The parents and F1 hybrids were grown in pots in the greenhouse from January to July, 2003.

\section{Anther culture}

First two to three panicles were collected from each genotype between 9.00 to 10.00 a.m. on sunny days when the distance between flag leaf and penultimate leaf was $5-7 \mathrm{~cm}$. Anthers of uni-nucleate stage (microscopic observation) were obtained from the spikelets of middle part of the panicles. The panicles were wrapped in
Table 1: A brief description of the parental rice varieties used

\begin{tabular}{ll}
\hline Genotype & Characteristics \\
\hline Hu Lo Tao & Japonica variety \\
Chuan 4 & Japonica variety \\
BG 90-2 & Indica, High yielding \\
BG 379-2 & Indica, High yielding, resistant to Brown \\
& Planthopper and Bacterial Blight \\
BG 94-1 & Indica, High yielding \\
Dahanala & Indica, Traditional variety \\
Suduru Samba Indica, Traditional variety, good grain \\
\end{tabular}

aluminium foil with moist cotton at the base of cut surface of the panicle and kept at $5^{\circ} \mathrm{C}$ for 7 days (Croughan, 1995) in sealed polyethylene bags.

The panicles were rinsed with $70 \%(\mathrm{v} / \mathrm{v})$ ethanol for 20 seconds. The spikelets were removed and they were surface sterilized with $30 \%(\mathrm{v} / \mathrm{v})$ commercial Clorox solution for 20 minutes and rinsed thoroughly with sterilized distilled water. Anthers were removed from the spikelets and cultured 100 anthers in $100 \times 15$ $\mathrm{mm}$ pettridishes with agar (Agar bacteriological No.1) solidified medium. The composition of the three callus induction medium used for anther culture establishment and plant regeneration medium is described in the Table 2. All the callus induction media were provided with kinetin $2.0 \mathrm{mg} / \mathrm{l}$ and 2,4-Dichlorophenoxy acetic acid (2,4-D) $1.0 \mathrm{mg} / \mathrm{l}$ and sucrose $5 \%$ $(\mathrm{w} / \mathrm{v})$. One pettridish constituted one replication and five replications for each genotype were cultured in each callus induction medium. The cultures were kept in the dark at $28^{\circ} \mathrm{C} \pm$ $2^{\circ} \mathrm{C}$ (Chen et al., 1991) for callus induction. The cultures were examined weekly up to 6 weeks and the callus induction frequency (percentage of anthers forming calli) was recorded on $6^{\text {th }}$ week.

\section{Plant regeneration}

The calli of 1-2 mm diameter were transferred to $100 \times 15 \mathrm{~mm}$ pettridishes containing $25 \mathrm{ml}$ of half strength (both macro and micro nutrients) Murashige and Skoog medium (Murashige and Skoog, 1962) supplemented with kinetin 2.0 $\mathrm{mg} / \mathrm{l}$ and $\alpha$-naphthaline acetic acid (NAA) 0.5 $\mathrm{mg} / \mathrm{l}$ (Croughan and Chu, 1991). The cultures were kept at constant white light $\left(50 \mu \mathrm{E} \mathrm{m}^{-2} \mathrm{~S}^{-1}\right)$ for $16 \mathrm{~h}$ at $28 \pm 2{ }^{\circ} \mathrm{C}$. The cultures were exam- 
ined weekly and the data on percentage of calli regenerating green and/or albino plants was recorded after 6 weeks of incubation. The experiment was repeated for three times and the data shown are per experiment mean \pm standard deviation (Takeuchi et al., 1997).

Shoots were transferred to half strength MS medium (supplemented with $0.5 \mathrm{mg} / \mathrm{l}$ NAA) for rooting. Regenerated plants were transferred to paddy soil in pots and grown to maturity in the green house. At maturity, spikelet fertility was measured as the ratio of number of grains per panicle to the total number of spikelets per panicle and expressed in percentage.

All the experiments were set in Completely Randomized Design and data were analyzed by the Statistical Analysis System (SAS Release 8.1) Analysis of Variance. Mean separation was done by Duncans' Multiple Range Test.

\section{RESULTS AND DISCUSSION}

\section{Effect of medium composition and genotype on callus induction}

In this study three different media (N6: Chu et al., 1975; B5: Gamborg et al., 1968; Miller: Miller, 1963) were used with some modifications based on the available literature for the callus induction. The major modifications made are shown in the Table 2. The sugar concentration of the media was increased to $5 \%$ $(\mathrm{w} / \mathrm{v})$ instead of $3 \%(\mathrm{w} / \mathrm{v})$ in general media. Chaleff and Stolarz (1981) have recommended the concentrations of $4-5 \%(w / v)$ of sucrose for the callus growth and differentiation. According to Chen (1978), high sucrose concentrations have differential promotive effects on callus induction in anthers of different developmentalstages.

All the media were provided with $2.0 \mathrm{mg} / \mathrm{l}$ 2,4-D and $1.0 \mathrm{mg} / \mathrm{l}$ kinetin (Huang et al., 1986). In this study callus induction media was constituted with one half the level of $\mathrm{NH}_{4}{ }^{+}$and double the level of $\mathrm{KNO}_{3}$ nitrogen of basic N6, B5 and Millers medium (Chen et al., 1991).

Callus induction started at three weeks of culture and the callus induction could be observed in both parents and F1 hybrids in all the media (Figure 1a). The frequency of callus formation varied between $0.2 \%$ to $29.4 \%$ depending on the genotype and culture medium (Table
3). Out of 17 genotypes evaluated, 12 responded better in N6 medium than B5 and Miller media. Callus induction frequency varied from 0.2 to $29.4 \%$ in N6 medium and 0.5 to $19.2 \%$ and 0.2 to $19.8 \%$ in B5 and Miller media respectively. The indica varieties had high callus induction frequencies in B5 medium than the other two media ranging from 0.5 to $9.4 \%$. The anther response of Japonica and F1 hybrids was quicker in N6 medium and formed visible callus after $3-4$ weeks compared to 5 6 weeks in the other two media. There was a significant genotypic effect on callus induction frequency among japonica, indica and F1 hybrids. Hu Lo Tao, Chuan 4 Japonica varieties and $\mathrm{Hu}$ Lo Tao $\times$ BG 90-2, Chuan $4 \times$ BG 902 F1 hybrids had wide adaptation to different medium constituents. Both of these Japonica varieties and F1 hybrids had the highest callus induction frequency in all the three media. The indica varieties BG 379-2, BG 94-1, Dahanala and Suduru samba had the least anther culture response in all three media. However, BG 90-2 variety had relatively high callus induction fre-

Table 2: Composition of the modified media used for callus induction and plant regeneration.

\begin{tabular}{|c|c|c|c|c|}
\hline \multirow{2}{*}{$\begin{array}{l}\text { Component } \\
(\mathrm{mg} / \mathrm{l})\end{array}$} & \multicolumn{3}{|c|}{ Callus induction media } & \multirow{2}{*}{$\begin{array}{l}\text { Plant regen- } \\
\text { eration me- } \\
\text { dium }\end{array}$} \\
\hline & N6 & $\mathbf{B 5}$ & Millers & \\
\hline$\left(\mathrm{NH}_{4}\right)_{2} \mathrm{SO}_{4}$ & 232 & 68 & - & - \\
\hline $\mathrm{NH}_{4} \mathrm{NO}_{3}$ & - & - & 500 & 1650 \\
\hline $\mathrm{KNO}_{3}$ & 3535 & 3125 & 2000 & 1900 \\
\hline $\mathrm{Ca}\left(\mathrm{NO}_{3}\right)_{2} \cdot 4 \mathrm{H}_{2} \mathrm{O}$ & - & - & 1000 & - \\
\hline $\mathrm{KH}_{2} \mathrm{PO}_{4}$ & 400 & - & 300 & 170 \\
\hline $\mathrm{MgSO}_{4} \cdot 7 \mathrm{H}_{2} \mathrm{O}$ & 185 & 250 & 35 & 370 \\
\hline $\mathrm{CaCl}_{2} \cdot 2 \mathrm{H}_{2} \mathrm{O}$ & 166 & 150 & - & 440 \\
\hline $\mathrm{H}_{3} \mathrm{BO}_{3}$ & 0.8 & 3 & 0.8 & 6.2 \\
\hline $\mathrm{MnSO}_{4} \cdot 4 \mathrm{H}_{2} \mathrm{O}$ & 4.4 & - & 4.4 & 22.3 \\
\hline $\mathrm{ZnSO}_{4} \cdot 7 \mathrm{H}_{2} \mathrm{O}$ & 1.5 & 2 & 1.5 & 8.6 \\
\hline $\mathrm{Na}_{2} \mathrm{MoO}_{4} \cdot 2 \mathrm{H}_{2} \mathrm{O}$ & - & 0.25 & - & 0.25 \\
\hline $\mathrm{CuSO}_{4} .5 \mathrm{H}_{2} \mathrm{O}$ & - & 0.025 & - & 0.025 \\
\hline $\mathrm{CoCl}_{2} \cdot 6 \mathrm{H}_{2} \mathrm{O}$ & - & 0.025 & - & 0.025 \\
\hline $\mathrm{KI}$ & 0.8 & 0.75 & 0.8 & 0.83 \\
\hline $\mathrm{FeSO}_{4} \cdot 7 \mathrm{H}_{2} \mathrm{O}$ & 27.85 & - & - & 27.85 \\
\hline $\mathrm{Na}_{2}$ EDTA & 37.25 & - & - & 37.25 \\
\hline Thiamine- $\mathrm{HCl}$ & 1 & 10 & 0.1 & 0.1 \\
\hline Nicotinic acid & 0.5 & 1 & 0.5 & 0.5 \\
\hline Pyridoxine- $\mathrm{HCl}$ & 0.5 & 1 & 0.1 & 0.5 \\
\hline Inositol & - & 100 & - & 100 \\
\hline Glycine & 2.0 & - & 2.0 & 2.0 \\
\hline Kinetin & 1.0 & 1.0 & 1.0 & - \\
\hline $2,4-\mathrm{D}$ & 2.0 & 2.0 & 2.0 & \\
\hline NAA & - & - & - & 0.5 \\
\hline
\end{tabular}

Source (for basic me- dia): Gamborg and Phillips, 1998 
Table 3: Effect of anther culture medium on callus induction from anthers of selected japonica, indica parental varieties and their F1 hybrids at 6 weeks after inoculations

\begin{tabular}{|c|c|c|c|}
\hline \multirow[t]{2}{*}{ Genotype } & \multicolumn{3}{|c|}{ Percentage \pm SD of calli formation } \\
\hline & N6 & B5 & Millers \\
\hline \multicolumn{4}{|l|}{ Parents } \\
\hline Hu Lo Tao & $19.6^{c} \pm 0.5$ & $14.2^{c} \pm 1.8$ & $11.0^{\mathrm{c}} \pm 1.8$ \\
\hline Chuan 4 & $16.8^{\mathrm{d}} \pm 3.2$ & $13.4^{\mathrm{c}} \pm 3.2$ & $13.6^{\mathrm{c}} \pm 1.6$ \\
\hline BG 90-2 & $7.4^{\mathrm{h}} \pm 1.8$ & $10.4^{\mathrm{de}} \pm 2.7$ & $6.6^{\mathrm{e}} \pm 1.9$ \\
\hline BG 379-2 & $1.4^{\mathrm{mn}} \pm 1.2$ & $4.0^{\mathrm{gh}} \pm 1.4$ & $0.4^{\mathrm{j}} \pm 0.4$ \\
\hline BG 94-1 & $0.8^{\text {no }} \pm 0.6$ & $2.4^{\mathrm{hi}} \pm 1.4$ & $0.2^{j} \pm 0.4$ \\
\hline Dahanala & $0.4^{\circ} \pm 0.4$ & $1.4^{\mathrm{hi}} \pm 1.0$ & $0.2^{\mathrm{j}} \pm 0.6$ \\
\hline Suduru Samba & $0.2^{\circ} \pm 0.2$ & $0.5^{\mathrm{i}} \pm 0.4$ & $0.2^{\mathrm{j}} \pm 0.2$ \\
\hline \multicolumn{4}{|l|}{ F1 Hybrids } \\
\hline Hu Lo Tao × BG 90-2 & $29.4^{\mathrm{a}} \pm 0.8$ & $19.2^{\mathrm{a}} \pm 1.4$ & $19.8^{\mathrm{a}} \pm 3.3$ \\
\hline Hu Lo Tao $\times$ BG 379-2 & $8.4^{\mathrm{g}} \pm 3.3$ & $5.6^{\mathrm{fg}} \pm 1.9$ & $5.2^{\mathrm{f}} \pm 2.2$ \\
\hline Hu Lo Tao × BG 94-1 & $4.7^{\mathrm{i}} \pm 1.3$ & $2.2^{\text {hi }} \pm 0.8$ & $2.2^{\mathrm{gh}} \pm 1.9$ \\
\hline Hu Lo Tao $\times$ Dahanala & $3.2^{\mathrm{lm}^{-}} \pm 1.9$ & $2.1^{\mathrm{hi}} \pm 1.4$ & $1.8^{\mathrm{j}} \pm 1.3$ \\
\hline $\begin{array}{l}\text { Hu Lo Tao } \times \text { Suduru } \\
\text { samba }\end{array}$ & $2.3^{\mathrm{k}} \pm 1.5$ & $4.4^{\mathrm{gh}} \pm 1.1$ & $2.4^{\mathrm{j}} \pm 1.5$ \\
\hline Chuan $4 \times$ BG 90-2 & $20.6^{b} \pm 2.5$ & $17.0^{\mathrm{b}} \pm 1.5$ & $16.6^{\mathrm{b}} \pm 2.7$ \\
\hline Chuan $4 \times$ BG 379-2 & $14.6^{\mathrm{e}} \pm 1.5$ & $11.8^{\mathrm{cd}} \pm 2.2$ & $9.8^{\mathrm{d}} \pm 1.9$ \\
\hline Chuan 4 × BG 94-1 & $9.4^{\mathrm{f}} \pm 2.4$ & $7.8^{\mathrm{ef}} \pm 1.9$ & $5.0^{\mathrm{f}} \pm 2.5$ \\
\hline Chuan $4 \times$ Dahanala & $4.8^{\mathrm{i}} \pm 1.9$ & $3.4^{\text {ghi }} \pm 2.0$ & $1.8^{\mathrm{g}} \pm 1.3$ \\
\hline Chuan $4 \times$ Suduru samba & $3.4^{\mathrm{j}} \pm 2.0$ & $2.2^{\mathrm{hi}} \pm 1.6$ & $2.0^{\mathrm{h}} \pm 2.1$ \\
\hline
\end{tabular}

In a column, mean followed by the same letter are not significantly different at 5\%

quency than the other indica varieties. The F1 hybrids Hu Lo Tao $\times$ BG 379-2, Hu Lo Tao $\times$ BG 94-1, Hu Lo Tao $\times$ Dahanala, Hu Lo Tao $\times$ Suduru samba, Chuan $4 \times$ BG 379-2, Chuan 4 $\times$ BG 94-1, Chuan $4 \times$ Dahanala and Chuan 4 $\times$ Suduru samba had intermediate anther culture response. This genotype dependency of the anther culture has been reported by Chen et al. (1991); Shih-Wei and Zhi-Hong (1992); Asad uzzaman, et al. (2003) in their previous studies.

The time requirement for the callus initiation was also genotype dependent. Japonica varieties and F1 hybrids the callus initiation could observe at three weeks. The indica varieties tested had callus initiation at five weeks.

\section{Plant regeneration from anther derived calli}

The plant regeneration started after two weeks from transfer. Some calli differentiated only in to green plantlets (Figure $1 \mathrm{~b}$ ) or albino plantlets. Some calli differentiated in to both green and albino plantlets. The medium used for callus induction and the genotype of the donor greatly affected the frequency of green plant regeneration. Highest green plant regeneration could be observed in $\mathrm{Hu}$ Lo Tao $\times$ BG 90-2 $(19.2-29.2 \%)$ and Chuan $4 \times$ BG 90-2 (17.7 $21.3 \%$ ) F1 hybrids in all three callus induction media tested (Table 4). Also the performance of Hu Lo Tao $\times$ BG 379-2 and Chuan $4 \times$ BG 379-2 comparatively high. The green plant regeneration frequency from the calli initiated on N6 medium was higher than the other two media in all the varieties and F1 hybrids. The regeneration frequencies varied between 0$29.2 \%$ in the N6 medium while the B5 medium varied between $0-20.1 \%$ and the Millers medium varied between $0-19.2 \%$. Among the parental rice varieties tested, $\mathrm{Hu}$ Lo Tao and Chuan 4 calli were more responsive for green plant regeneration.

The frequency of albino plant regeneration from calli initiated on N6 medium and B5 medium was also high and the values varied between $0-30.4 \%$ in N6 medium and $0-35.4 \%$ on B5 medium. Regeneration of albino plants has been reported as a major problem in rice anther culture especially in indica rice (Asaduzzaman, et al., 2003; Chen et al., 1991; Shi-Wei and Zhi -Hong, 1991). According to Roy and Mandal (2005), generally green plant regeneration from

Table 4: Green and albino plant regeneration from anther derived calli (N6 medium) of selected japonica, indica rice varieties and their $\mathrm{F} 1$ hybrids

\begin{tabular}{|c|c|c|c|}
\hline \multirow[t]{2}{*}{ Genotype } & \multicolumn{3}{|c|}{$\begin{array}{c}\text { Percentage calli regener- } \\
\text { ating shoots }\end{array}$} \\
\hline & $\begin{array}{c}\text { Green } \\
\text { (G) }\end{array}$ & $\begin{array}{l}\text { Albino } \\
\text { (A) }\end{array}$ & G/ A \\
\hline Parents & & & \\
\hline Hu Lo Tao & $22.5^{\mathrm{b}}$ & $21.5^{\mathrm{a}}$ & 1.04 \\
\hline Chuan 4 & $16.0^{\mathrm{c}}$ & $19.0^{\mathrm{a}}$ & 0.84 \\
\hline BG 90-2 & $1.0^{\mathrm{ef}}$ & $3.0^{\mathrm{cd}}$ & 0.33 \\
\hline BG 379-2 & - & - & - \\
\hline BG 94-1 & - & - & - \\
\hline Dahanala & - & - & - \\
\hline $\begin{array}{r}\text { Suduru Samba } \\
\text { F1 Hybrids }\end{array}$ & - & - & - \\
\hline Hu Lo Tao × BG 90-2 & $41.0^{\mathrm{a}}$ & $22.0^{\mathrm{a}}$ & 1.86 \\
\hline Hu Lo Tao $\times$ BG 379-2 & $3.0^{\mathrm{e}}$ & $10.0^{\mathrm{b}}$ & 0.3 \\
\hline Hu Lo Tao × BG 94-1 & - & $7.0^{\mathrm{bc}}$ & - \\
\hline Hu Lo Tao $\times$ Dahanala & - & $1.0^{\mathrm{cd}}$ & - \\
\hline Hu Lo Tao $\times$ Suduru samba & - & - & - \\
\hline Chuan $4 \times$ BG 90-2 & $11.5^{\mathrm{d}}$ & $23.0^{\mathrm{a}}$ & 0.5 \\
\hline Chuan $4 \times$ BG 379-2 & $1.0^{\mathrm{ef}}$ & $18.0^{\mathrm{a}}$ & 0.3 \\
\hline Chuan 4 × BG 94-1 & - & $12.0^{\mathrm{b}}$ & - \\
\hline Chuan $4 \times$ Dahanala & - & $2.0^{\mathrm{cd}}$ & - \\
\hline Chuan $4 \times$ Suduru samba & - & $2.0^{\mathrm{cd}}$ & - \\
\hline
\end{tabular}



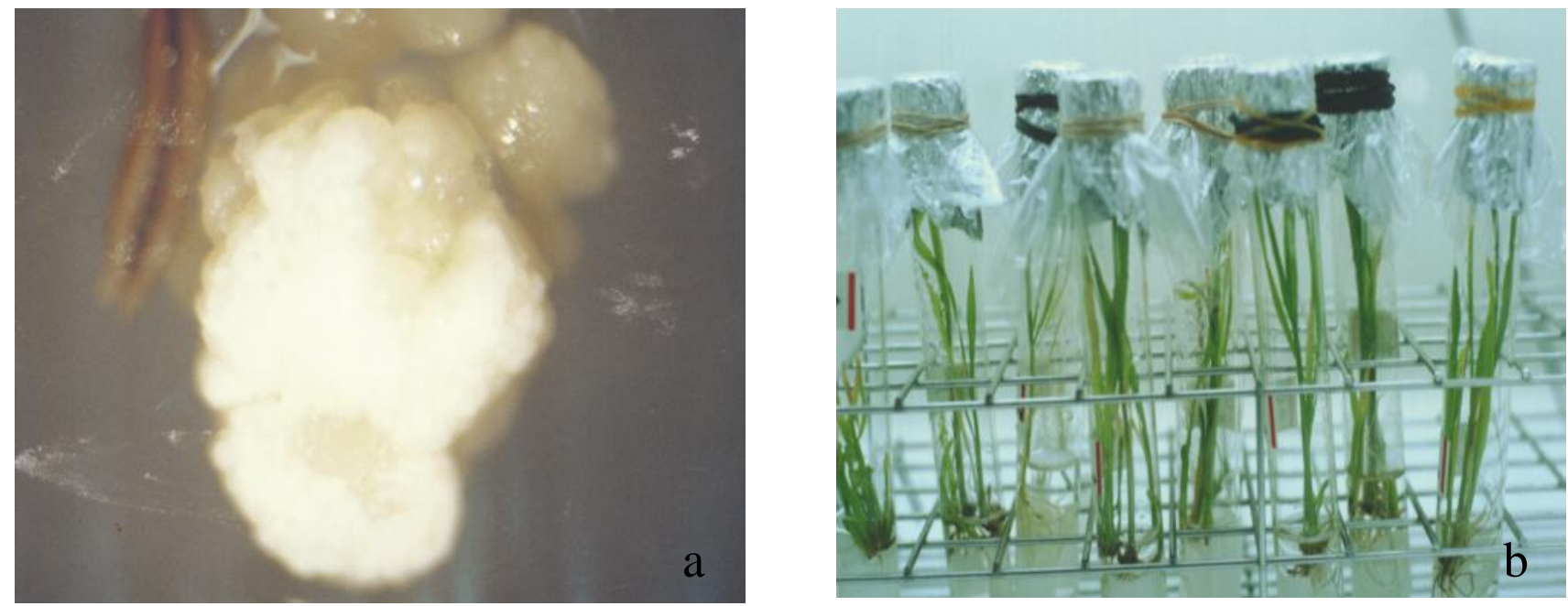

Figure 1: Callus induction and plant regeneration, a: magnified rice anther showing callus development at 6 weeks of culture, b: green rice plantlets developed from anther drived calli

Table 5: Transplanting survival, spikelet fertility of the anther derived indica, japonica varieties and their F1 hybrids

\begin{tabular}{|c|c|c|c|c|c|c|}
\hline \multirow[t]{2}{*}{ Genotype } & \multicolumn{3}{|c|}{ Transplanting survival } & \multicolumn{3}{|c|}{ Spikelet fertility } \\
\hline & Plants transferred & Plants survived & Percentage survival & $0 \%$ & $1-5 \%$ & $>5 \%$ \\
\hline \multicolumn{7}{|l|}{ Parents } \\
\hline Hu Lo Tao & 32 & 20 & 62.5 & 1 & 4 & 15 \\
\hline Chuan 4 & 24 & 18 & 75.0 & 3 & 6 & 9 \\
\hline BG 90-2 & 3 & 2 & 66.6 & 2 & - & - \\
\hline \multicolumn{7}{|l|}{ F1 Hybrids } \\
\hline Hu Lo Tao × BG 90-2 & 81 & 43 & 53.0 & 21 & 15 & 2 \\
\hline Hu Lo Tao × BG 379-2 & 4 & 3 & 75.0 & 3 & - & - \\
\hline Chuan $4 \times$ BG 90-2 & 19 & 13 & 68.4 & 8 & 3 & 2 \\
\hline
\end{tabular}

androgenic calli is very low and low anther culture response, high percent of albino plant regeneration are the principle constraints in establishing successful anther culture in rice.

The green/ albino plant regeneration ratio of the Hu Lo Tao $\times$ BG 90-2 was high from the calli initiated on all the three callus induction media tested compared to all the other varieties and F1 hybrids tested. However this ratio of most of the genotypes remained low. As ShihWei and Zhi-Hong (1991) have stated, the frequency of albinism depend on the varieties or hybrids used, anther pre treatment temperature and the culture medium constituents.

Transplanting and growing of anther derived plants

Plantlets transplanted in to pots had $50-75 \%$ survival rate and they were grown to maturity (Table 5). The spikelet fertility varied considerably depending on the genotype. Out of 99 the plants survived, 36 plants were completely sterile, 28 had $1-5 \%$ spikelet fertility and 28 had $>5 \%$ spikelet fertility.

Modified N6 medium has pleasing effect on the callus induction performance in indica $x$ japonica hybrids as well as japonica parents. The medium used for callus induction and the genotype greatly affects in the plant regeneration.

\section{REFERENCES}

Asaduzzaman, M. Bari, M.A. Rahman, M.H. Khatun, N., Islam, M.A. and Rahman, M. (2003) In-vitro plant regeneration Through anther culture of five rice varieties. Online Journal of Biological Sciences: 3 (2): 167 171

Balachandran, S.M., Sarma, N.P. and Siddique, E.A. (1999) Inheritance of anther culture response in rice. Current Science; 77 (7); 962-964 
Chaleff, R.S. and Stolarz, A. (1981) Factors influencing the frequency of callus formation among cultured rice (Oryza sativa) anthers. Physiol. Plant. 51: 201-206

Chen, C.C., Tsay, H.S. and Huang, C.R. (1991) Factors affecting androgenesis in rice (Oryza sativa L.). In Biotechnology in Agriculture and Forestry: 14: Rice. Ed. Bajaj, Y.P.S. Springer Verlag. Berlin 193-211

Chen, C.C. (1978) Effects of sucrose concentration in plant production in Anther culture in rice. Crop Sci. 18: 905-906

Chu, C.C., Wang, C.S., Sun, C.S., Hsu, C., Yin, K.C., Chu, C.Y. and Bi, F.Y. (1975) Establishment of an efficient medium for anther culture of rice through comparative experiments on the nitrogen sources. Science Sinica. 18: 659-668

Croughan, T.P. (1995) Anther culture of doubled haploid production. In Plant Cell Tissue and Organ Culture. Eds. Gamborg, O.L. and Phillips, G. C. Narosa Publishing House. New Delhi. 143-154

Croughan, T.P. and Chu, Q.R. (1991) Rice (Oryza sativa L.). Establishment of callus cultures and the regeneration of plants. In Biotechnology in Agriculture and Forestry: 14: Rice. Ed. Bajaj, Y.P.S. Springer Verlag. Berlin. 19-37

Datta, S.K. (2005) Androgenic haploids: Factors controlling development and its application in crop improvement. Current Science. 89 (11): 1870-1878

Gamborg, O.L., Miller, R.A. and Ojima, K. (1968) Nutrient requirements of suspension cultures of soybean root cells. Ex. Cell Res. 50: $151-158$

Gamborg, O.L. and Phillips, G.C. (1998) Plant Cell Tissue and Organ Culture. Narosa Publishing House. London. 348

Huang, C.R., Wu, Y.H. and Chen, C.C. (1986) Effects of plant growth substances on callus formation and plant regeneration in anther culture of rice. In Rice Genetics. Proc. of International Rice Genetics Symposium: IRRI; 763-771

Miller, C.O. (1963) Kinetin and Kinetin like compounds. In Moderne der pflanzenanalyse. 6: 194-202

Murashige, T.P. and Skoog, F. (1962) A revised medium for rapid growth and bioassays with tobacco tissue culture. Physiol. Plant. 15 (3): 473-497
Raina, S.K. and Zapata, F.J. (1997) Enhanced anther culture efficiency of indica rice (Oryza sativa L.) through modification of the culture media. Plant Breed. 116: 305315

Reddy, V.S. , Leelawathi, S. and Sen, S.K. (1985) Influence of genotype and culture medium on microspore callus induction and green plant regeneration in anthers of Oryza sativa. Physiol. Plant. 63: 309- 314

Roy, B. and Mandal, A.B. (2005) Anther culture response in indica rice and variations in major agronomic characters among the androclones of a scented cultivar Karnal local. African Journal of Biotechnology. 4 (3): 235-240

Senadhira, D., Zapatha-Aris, F.J., Gregorio, G.B., Alejar, M.S., Cruz, H.C., Padolina, T.F. and Galvez, A.M., (2002) Development of the first salt-tolerant rice cultivar through indica/ indica anther culture. Field Crops Res. 76: 103-110

Shih-Wei, L. and Zhi-Hong, X. (1992) Anther culture for rice improvement in China. In Biotechnology in Agriculture and Forestry: 14: Rice. Ed. Bajaj, Y. P. S. Springer Verlag. Berlin. 19-37

Snape, J.W. (1989) Doubled haploid breeding theoretical basis and practical applications. In Review of Advances in Plant Biotechnology. Eds. Kazi, A.M. and Stich, L. CIMMYT and IRRI. 19-30

Takeuchi, Y., Abe, T. and Sasahara, T., (1997) Genetic analysis of plant regeneration from seed derived calli in rice (Oryza sativa L.). Crop Sci. 37: 963 - 965

Wang, M., Sandra, V.B. and Bert, V.D. (2000) Insights in to a key developmental switch and its importance for efficient plant breeding. Plant Physiology. 124: 523-530

Yi, F.P. (1991) Breeding new rice strains through anther culture. In Biotechnology in Agriculture and Forestry: 14: Rice. Ed. Bajaj, Y.P.S. Springer Verlag. Berlin. 116129

Zhang, Z.H. (1989) The practicability of anther culture breeding in Rice. In Review of Advances in Plant Biotechnology. Eds. Kazi, A.M. and Stich, L. CIMMYT and IRRI. 31 $-42$ 